\title{
Microstructural Characterization of Ti-6Al-7Nb Alloy After Severe Plastic Deformation
}

\author{
Juno Gallego ${ }^{a *}$, Tiago Santos Pinheiro ${ }^{\text {b }}$, Ruslan Zufarovich Valiev ${ }^{c}$,Veronika Polyakovac,
}

Claudemiro Bolfarini ${ }^{\text {, }}$ Cláudio Shyinti Kiminami ${ }^{\text {b }}$ Alberto Moreira Jorge Jr. ${ }^{b}$, Walter José Botta ${ }^{b}$

\author{
${ }^{a}$ Department of Mechanical Engineering, São Paulo State University - UNESP, \\ Ilha Solteira, SP, Brazil \\ ${ }^{\mathrm{b}}$ Department of Materials Engineering, Federal University of São Carlos - UFSCar, \\ São Carlos, SP, Brazil \\ 'Institute of Physics of Advanced Materials, Ufa State Aviation Technical University, \\ 450000, 12 K. Marx Street, Ufa, Russia
}

Received: January 1, 2012; Revised: April 17, 2012

\begin{abstract}
The ASTM F1295/Ti-6Al-7Nb alloy present mechanical properties and biocompatibility very attractive for application in medical and dental implants. In this context, processing of these Ti-based alloys by severe plastic deformation (SPD) has been extensively reported recently. However, the mechanical properties of equal channel angular pressed (ECAP) ASTM F1295 alloy are still a matter of research. In the present study, Ti-6Al-7Nb samples were processed by ECAP following thermomechanical processing which effects on the microstructure of Ti-6Al-7Nb alloy were investigated by X-ray diffraction (XRD) and transmission electron microscopy (TEM). The analyses have shown that the microstructure was composed by ultrafine grains (UFG) with sizes ranging from 200 to $400 \mathrm{~nm}$. Ring-type selected area electron diffraction patterns (SAEDP) suggested the co-existence of low- and high-angle grain boundaries. Some regions of the samples have presented evidences of the presence of grains with unfavorable orientation to the plastic deformation. These grains can act as rigid bodies and concentrate the deformation in its surrounding areas, as an "open-die grain" mechanism. Such deformation mechanism could be attributed to the differences in the plastic behavior between the alpha and beta titanium phases.
\end{abstract}

Keywords: Ti-6Al-7Nb alloy, ECAP, ultra-fine grained microstructure, XRD, TEM

\section{Introduction}

Materials for biomedical applications should have optimal levels of strength and toughness, and stable chemically and biocompatible. About that, titanium alloys have presented exceptional corrosion resistance due to an oxide layer formed on surface, which contribute osteointegration properties. In addition, titanium alloys have showed an elasticity modulus closer to bones than biomedical stainless steels, decreasing risk of catastrophic failure during prostheses service life ${ }^{1}$.

Ti-6Al-4V alloy (ASTM F1108) has been used to manufacturing orthopedic prostheses and dental implants due to its biomechanical properties. However, the presence of vanadium can be considered problematic if ions of that element are introduced into human tissues, due to its histotoxic behavior. A harmless material as Ti-6Al-7Nb alloy (ASTM F1295) was developed more recently, where similar properties were obtained substituting vanadium by niobium as the BCC (beta-Ti) stabilizing element. Niobium has showed excellent biocompatibility and aluminum is responsible by significant solid strengthening of HCP titanium ${ }^{2}$. The microstructure of both alloys is composed

e-mail: gallego@dem.feis.unesp.br by alpha-Ti (HCP) and beta-Ti phases, which result in good compromise for biomechanical applications ${ }^{3,4}$.

The mechanical properties of Ti-6Al-7Nb alloy are strongly affected by microstructure, which refining increases both strength and toughness. Due to the low amount of BCC beta-phase, it is not possible a significant strengthening of ASTM F1295 alloy by means of quenching and ageing treatments. The most effective strengthening can be achieved by thermomechanical processing. Severe plastic deformation (SPD) can be used to that propose, being equal channel angular pressing (ECAP) one of most important techniques to achieve an effective grain refining ${ }^{5-8}$. The aim of this work was to investigate the microstructure of the Ti- $6 \mathrm{Al}-7 \mathrm{Nb}$ alloy after ECAP followed by thermomechanical treatment, using mainly transmission electron microscopy and X-ray diffraction. There were observed evidences that probable differences in the plastic behavior between neighbor grains can act as an "open-die" nanodeformation mechanism during ECAP of the investigated alloy.

\section{Experimental Procedure}

The chemical composition of Ti-6Al-7Nb (ASTM F1295) alloy is presented in Table 1. Specimens were 
submitted to thermomechanical treatment according procedure showing in Figure 1, carried out by Professor Ruslan Z. Valiev and his group 9 . Solubilization followed by water quenching and overageing was carried out before thermomechanical processing. Specimens were processed by ECAP using a $120^{\circ}$ die and route $\mathrm{B}_{\mathrm{C}}$. Six passes of deformation were performed at starting temperature of $600{ }^{\circ} \mathrm{C}$ following hot (4 passes at $300{ }^{\circ} \mathrm{C}$ ) and cold extrusion. The thermomechanical processing was finished with a stress-relief annealing at $500{ }^{\circ} \mathrm{C}$ during 1 hour. The formation of an ultra-fine grain (UFG) structure was achieved after extrusion and stress-relief annealing for additional strengthening and shape forming. As a result, cylindrical rods with a diameter of $14 \mathrm{~mm}$ and $200 \mathrm{~mm}$ length were obtained. Samples of as received and ECAP condition were prepared for analysis by X-ray diffraction (XRD), scanning electron microscopy (SEM) and transmission electron microscopy (TEM).

The preparation of metallographic samples was made according to conventional procedure, where $1.0 \mu \mathrm{m}$ alumina was used to final mechanical polishing. Polished samples were analyzed by XRD which was carried out in a Siemens ${ }^{\mathrm{TM}}$ DL-5005 diffractometer operated with monochromatic $\mathrm{Cu}-\mathrm{K} \alpha_{1}$ radiation $(\lambda=154.05 \mathrm{pm})$. Diffraction spectra were collected from 20 to 90 degrees $2 \theta$ range, with a step scan of 2 degrees per minute. The XRD patterns were compared with Crystallographic Information Files (CIF) available from the Inorganic Crystal Structure Database (ICSD) ${ }^{10}$. The microstructure was revealed after Kroll etching $(92 \mathrm{~mL}$ distilled water, $6 \mathrm{~mL}$ nitric acid and $2 \mathrm{~mL}$ hydrofluoric acid) during few seconds. The SEM observation was performed in a Philips ${ }^{\mathrm{TM}}$ XL-30 equipped with field emission gun and electron dispersive spectroscopy (EDS) microanalysis.

Thin foil TEM samples were prepared from both transversal and longitudinal section of the ECAPed pieces. Small thin pieces were cut from bars with diamond

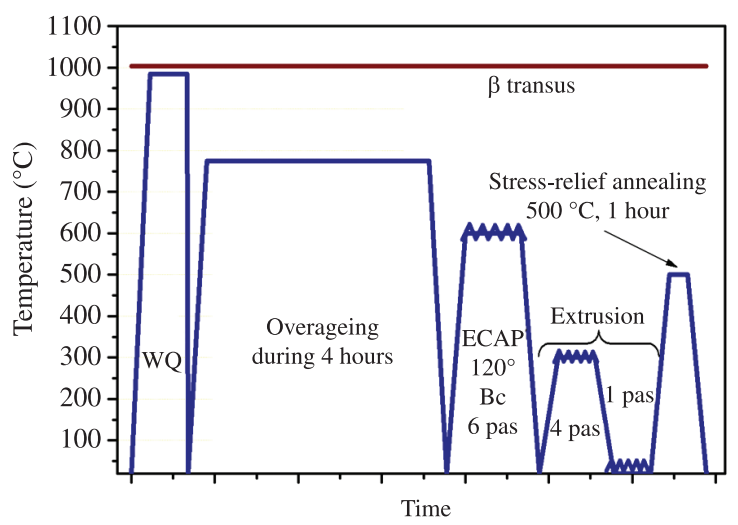

Figure 1. Thermomechanical processing used to formation of UFG structure of the Ti-6Al-7Nb alloy (schematic). After Semenova et al. ${ }^{9}$.

Table 1. Chemical composition of Ti-6Al-7Nb (ASTM F1295) alloy (wt. (\%)).

\begin{tabular}{cccccc}
\hline Al & $\mathbf{N b}$ & $\mathbf{F e}$ & $\mathbf{N}$ & $\mathbf{O}$ & $\mathbf{T i}$ \\
\hline 6.17 & 7.05 & 0.14 & 0.03 & 0.17 & bal. \\
\hline
\end{tabular}

wheel, being carefully ground up to 50-70 $\mu \mathrm{m}$ thick and punched in $3.0 \mathrm{~mm}$ diameter disks with appropriate device. Transparent areas for electron beam were obtained after grinding and dimpler with Gatan ${ }^{\mathrm{TM}}$ Precision Ion Polishing System (PIPS). The TEM observations were carried out in a Philips ${ }^{\mathrm{TM}}$ CM120 microscope equipped with an EDS microanalysis device operated at $120 \mathrm{kV}(\lambda=3.35 \mathrm{pm})$ with a standard calibrated camera length $(\lambda \mathrm{L}=36.4 \AA$ A.mm). Selected Area Electron Diffraction (SAED) analyses were performed with Java Electron Microscopy Simulation software - JEMS ${ }^{\circledR}$. Convergent Beam Electron Diffraction (CBED) was applied for evaluating crystallographic misfit between ultrafine grains. It was used a $30 \mathrm{~nm}$ spot size electron beam collimated on the central region of each grain, under a nominal camera length of $470 \mathrm{~mm}$ for recording of the CBED patterns.

\section{Results and Discussion}

The SEM micrograph presents in Figure 2 shows that microstructure of as received condition is formed by two phases. The contrast obtained by SEM suggests that dark regions present some prismatic morphology, 5-10 $\mu \mathrm{m}$ grain size and larger volume fraction, surrounded by bright lath regions. Qualitative chemical investigations performed by electron dispersive spectroscopy (EDS) analysis during SEM observations have indicated that further phase is aluminum-rich while latter one is niobium-rich.

The results obtained by XRD analyses on as received and ECAPed samples are showed in Figure 3. Diffracted peaks present in all samples are consistent with $\{\mathrm{hkl}\}$ reflections indicated by hexagonal close-packed alpha-Ti (ICSD \#44390 card) and body-centered cubic beta-Ti (ICSD \#44391 card). These results are agreement with SEM analyses because aluminum is considered a strong alpha-Ti stabilizer while niobium is a beta-Ti former. Due to the presence of $\mathrm{Nb}$ and $\mathrm{Al}$ substitutional atoms in its crystal lattice, improved fitting of the Ti-6Al-7Nb XRD results were obtained with a slightly change in " $a$ " lattice parameter: from $295.0 \mathrm{pm}$ to $292.5 \mathrm{pm}$.

The severe plastic deformation promoted some texture in ECAPed samples. There are different intensities for same reflection indicated either longitudinal or transversal

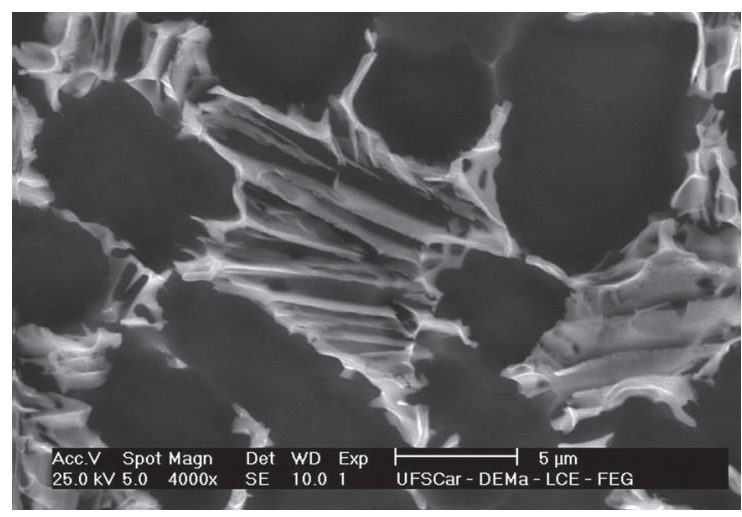

Figure 2. SEM micrograph shows typical microstructure of the Ti-6Al-7Nb alloy in as-received condition. 
sections in Figure 3. Full-width half-maximum of diffracted peaks suggest that probably some residual stress may be present after SPD processing and/or very fine crystallites can be found in the microstructure of the investigated alloy.

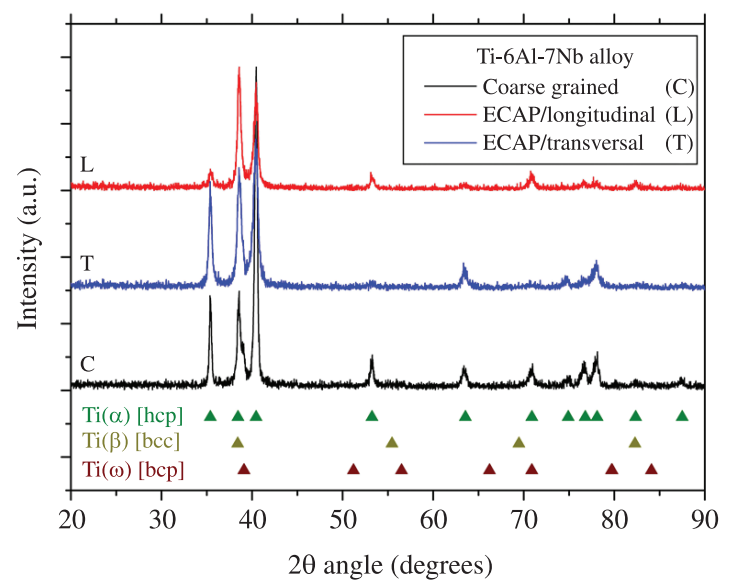

Figure 3. XRD patterns obtained from as received and thermomechanical treated samples.
TEM observations carried out in thin foil ECAPed samples show significant grain refining. Figure 4 a present a typical equiaxed grain structure found in transversal section, with 200-400 nm size. The visibility of grain boundaries in some regions is sometimes very poor in bright field $(\mathrm{BF})$ contrast due to the presence of bend contours and small angular misfit between neighboring grains, as reported by Cabibbo and colleagues ${ }^{11}$. The formation of dislocation substructure was not observed in the transversal section. SAED analyses as illustrated in Figure $4 \mathrm{~b}$ have showed that these regions are polycrystalline due to the formation of typical ring-type patterns, where some texture effects can be observed with stronger spots occupying well-defined arc sectors. Indexing SAED by JEMS software confirm that samples are mainly composed by alpha-Ti. Selecting diffracted spots by objective aperture is possible obtaining a dark field (DF) contrast, Figure 4c, which was applied to determine the ultrafine grain size. EDS microanalyses have indicated that the amount of aluminum ranged from 4.2 to $4.7 \mathrm{wt}$. (\%) and niobium between 6.2 to $7.7 \mathrm{wt}$ ( $(\%)$. Figure $4 \mathrm{~d}$ represents an example of that investigation.

Figure 5 presents the microstructure of longitudinal section of the ECAPed samples. It can be noted that are some grains with 500-1500 nm length and higher elongation

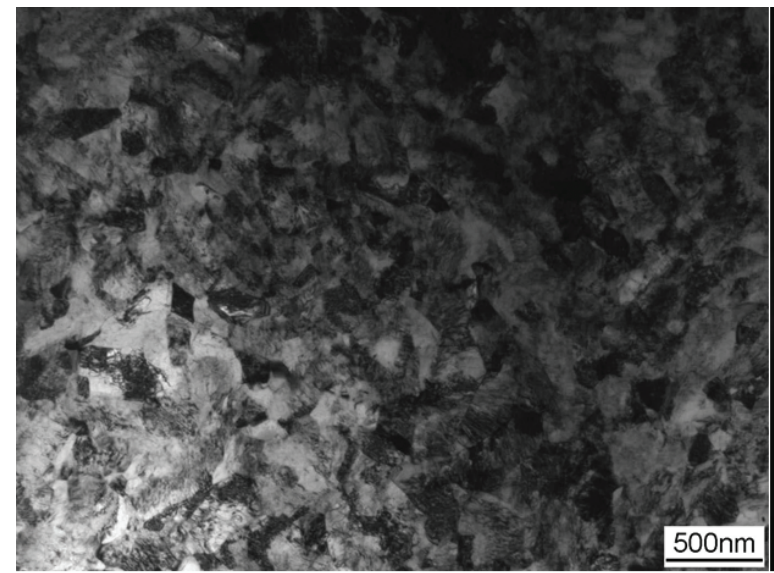

(a)

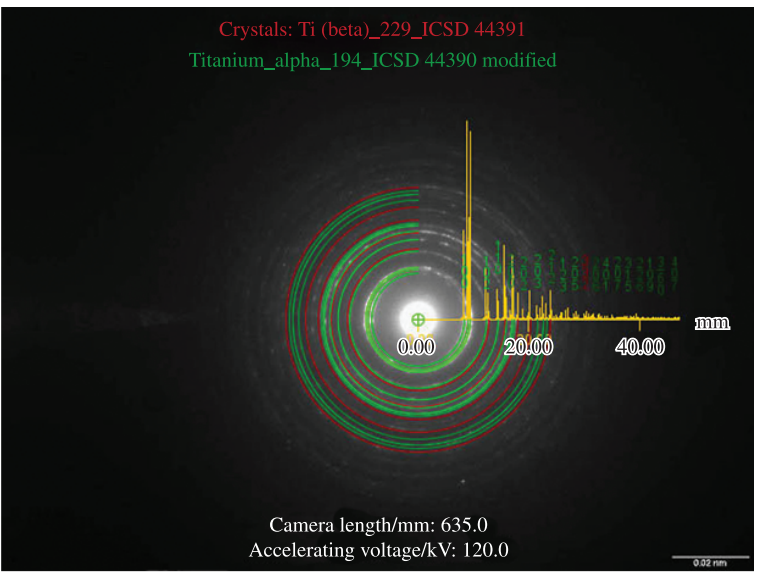

(b)

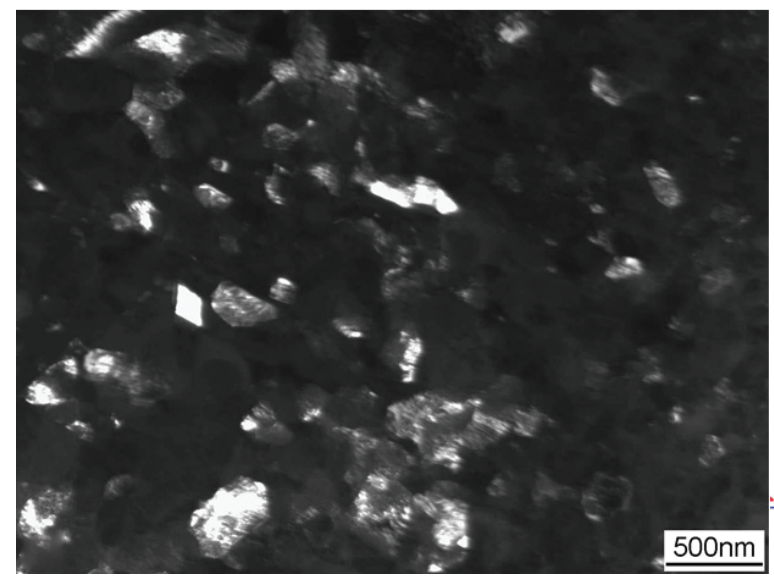

(c)

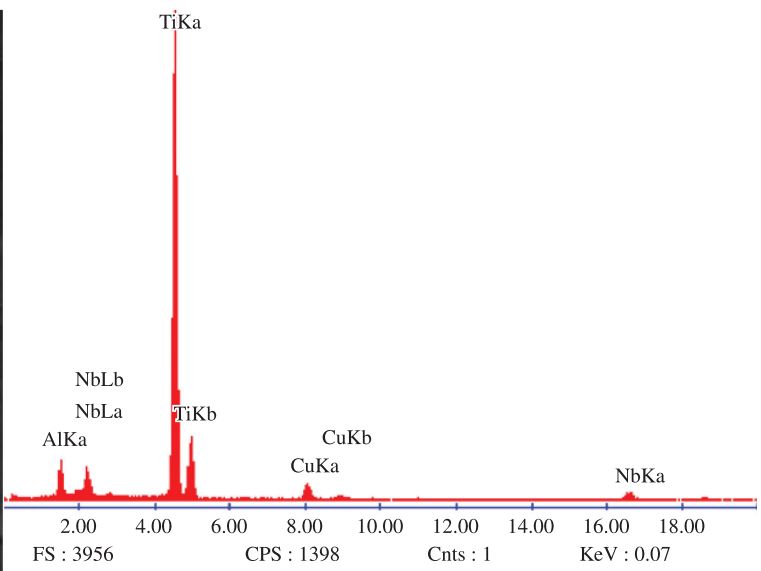

(d)

Figure 4. BF TEM micrograph in (a) showing ultrafine grain microstructure and its correspondent ring-type SAED pattern in (b). DF contrast presented in (c) came from same area showed in (a). Typical EDS microanalysis of a grain in (d). 


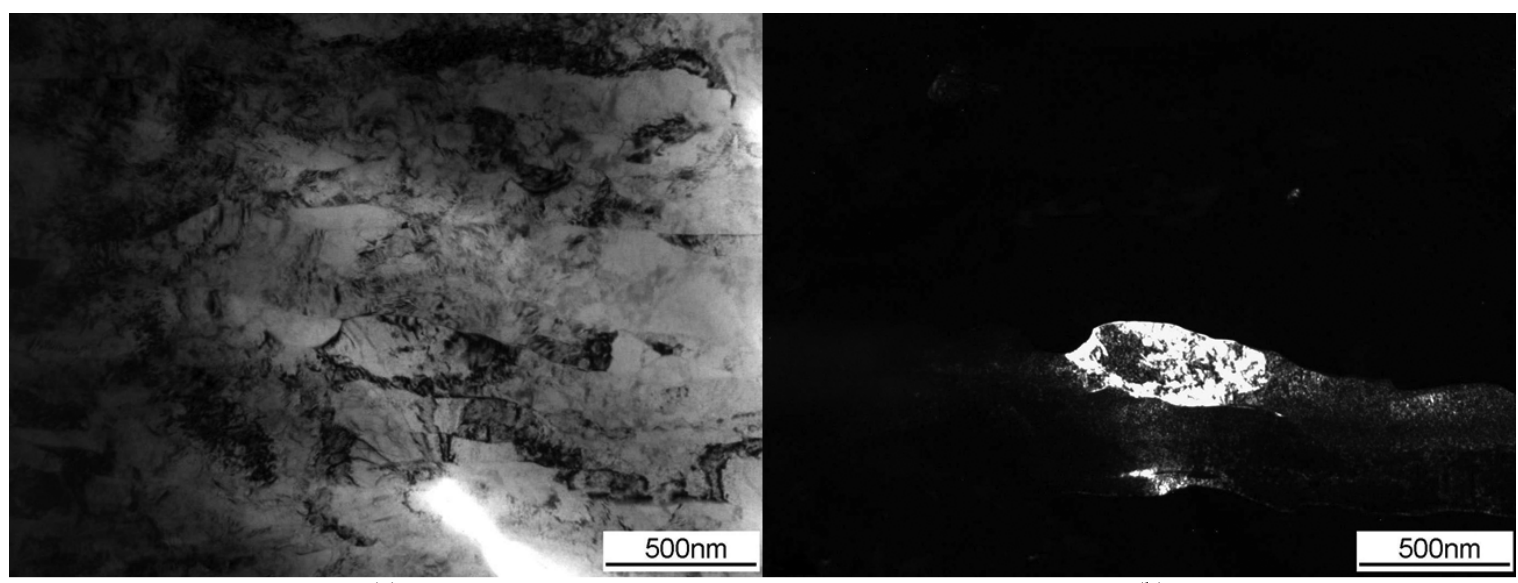

(a)

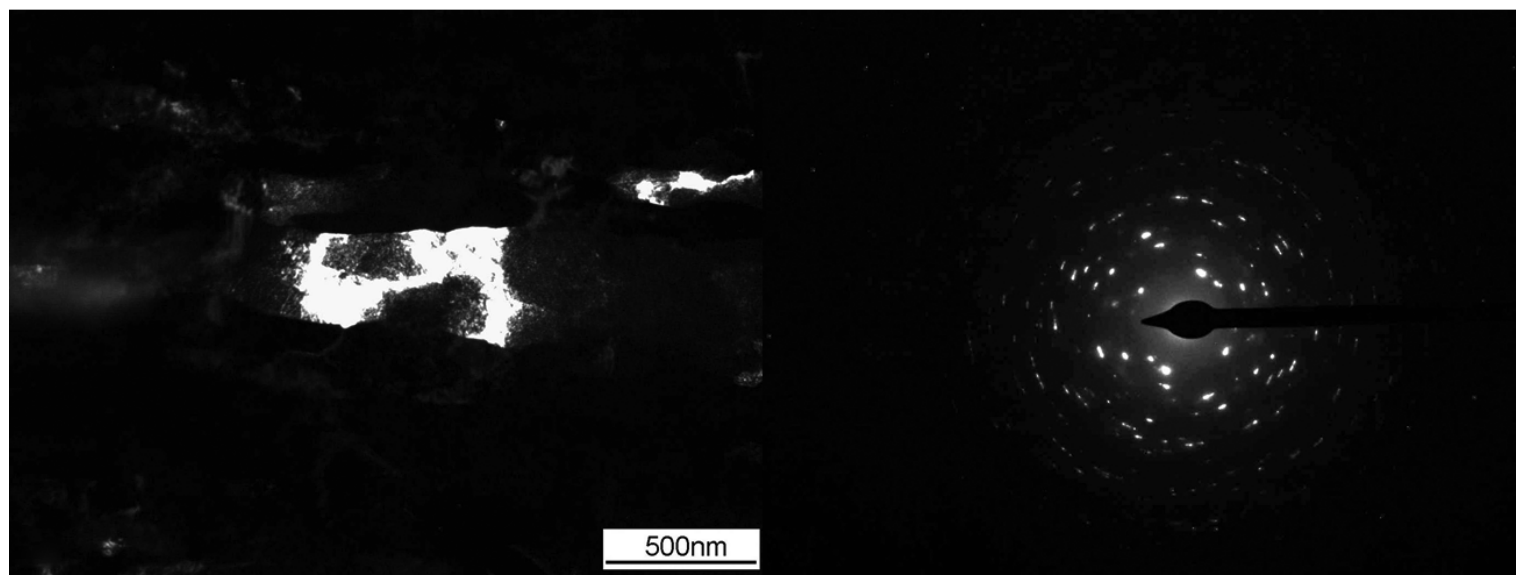

(c)

(d)

Figure 5. TEM micrographs of the same area in BF (a) and DF (b, c) showing elongated grain microstructure with "fragmented contrast". The respective SAED pattern is presented in (d).

(aspect ratio) resulting from plastic flow during processing. As verified during transversal section observation, the visualization of the grain boundaries in BF contrast was harmed, Figure 5a, because of non-equilibrium processing ${ }^{5,6}$. DF contrast has revealed an interesting feature inside of elongated grains that have seemed "fragmented", Figures 5b, c. In this kind of contrast, some regions of a grain present stronger intensity than other ones and it has been already observed in commercially pure titanium processed by warm $\mathrm{ECAP}^{12}$. The objective aperture collected diffracted electrons from nearest regions with very small crystallographic misfit, resulting heterogeneous distribution of the diffraction intensities. As apparently these regions are not separated by dislocation arrays, it is possible that localized elastic strains are associated to the creation of these sub-domains. In similar operational conditions, a small number of elongated grains could be selected by SAD aperture that was resulting in a partial ring-type SAED pattern - compare Figure 5d with Figure 4b.

The effect of ECAP processing on the contrast of the microstructure obtained by TEM is quite complex. There are some regions, as showed in Figure 6, where grain boundaries can be or not well defined and even a smallest SAD aperture has selected several grains. In an ultrafine microstructure, the application of convergent beam electron diffraction (CBED) can be the most recommended technique to determine crystallographic orientation. In Figure 6 there are neighbor grains with similar contrast (e.g. \#1 and \#5; \#6 and \#7), where CBED shows that their orientations are different.

The TEM micrographs showed some evidences that the contrast inside the ultrafine microstructure is complex and not uniform, as reported previously ${ }^{12,13}$. We can classify this variation in two classes, both exemplified in Figure 7: (i) grains with "intercalated" contrast, i.e. the objective aperture has selected diffracted electrons from contiguous areas that present reasonable crystallographic misfit - as the $\mathrm{x}$-Y-x segment where a non-diffracting grain (dark) separates two diffracting (bright) grains; (ii) contrast fragmentation in a grain with small misfit, as represented in Figure 7 by a-b curved line. In this case the contrast is quite similar, but not equal, between regions not well defined of the same grain. Inexistence of dislocation arrays, probably eliminated during stress-relief annealing ${ }^{12}$, suggests that this contrast can be resulting from a small angular misalignment of the diffraction conditions. In same example, we can observe an "intrusion" of the $\mathrm{W}$ and $\mathrm{Z}$ grains - acting as a "nano open-die" - on a prior elongated grain (line a-b). These 
grains act as rigid bodies and concentrate the deformation in its surrounding areas. That "intrusion grain deformation mechanism" would be possible during the ECAP if the crystal orientation of $\mathrm{Z}$ and $\mathrm{W}$ grains was not favorable for the plastic deformation due to differences in the plastic behavior between alpha and beta titanium phases or these grains were composed by harder phases. Therefore, further TEM investigations should be directed towards the application of proposed mechanism during ECAPing of the Ti-6Al-7Nb alloy.

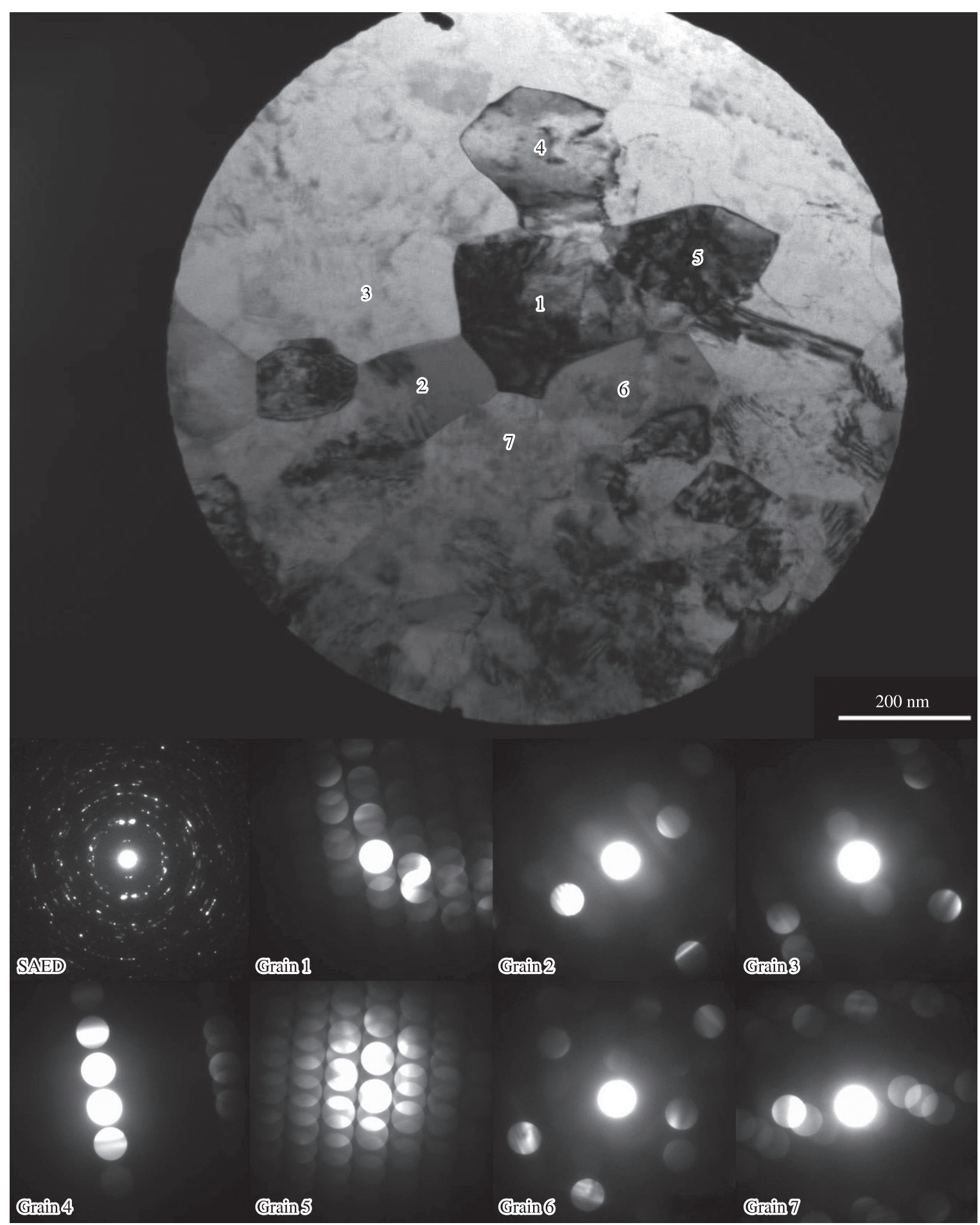

Figure 6. BF TEM micrograph taken from transversal section, where some ultrafine grains were selected by smaller SAED aperture. Ring-type SAED pattern indicates poly crystal area. CBED applied on indicated grains suggest that misfit among grains with similar contrast can be relatively small, e.g. grains \#1 and \#5. CBED spot size: $30 \mathrm{~nm}$. 


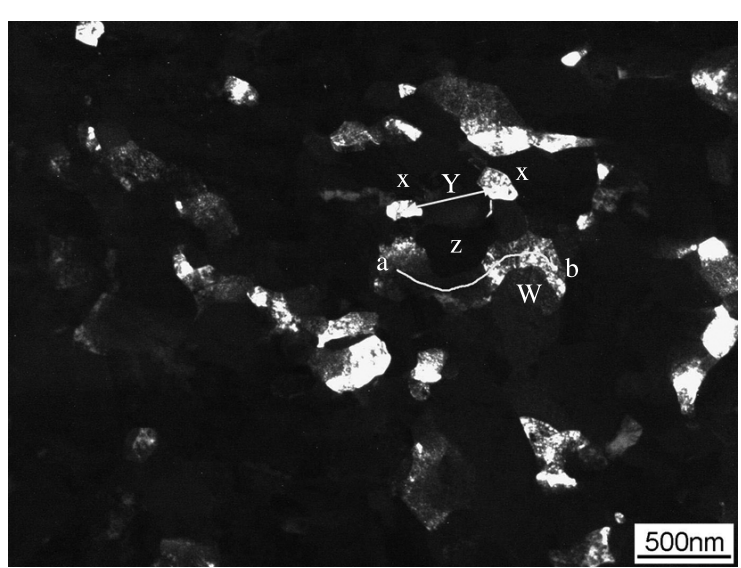

Figure 7. DF TEM micrograph showing fragmented contrast inside ultrafine grains and an example of the "intrusion grain deformation mechanism". See text for details.

\section{References}

1. Niinomi M. Recent research and development in titanium alloys for biomedical applications and healthcare goods. Science and Technology of Advanced Materials. 2003; 4:445-454. http:// dx.doi.org/10.1016/j.stam.2003.09.002

2. Khan MA, Williams RL and Williams DF. The corrosion behaviour of Ti-6Al-4V, Ti-6Al-7Nb and Ti-13Nb-13Zr in protein solutions. Biomaterials. 1999; 20:631-637. http:// dx.doi.org/10.1016/S0142-9612(98)00217-8

3. Polyakova V, Semenova I and Valiev RZ. Influence of annealing on the structure and mechanical properties of ultrafine-grained alloy Ti-6Al-7Nb, processed by severe plastic deformation. Materials Science Forum. 2011; 667-669:943-948. http:// dx.doi.org/10.4028/www.scientific.net/MSF.667-669.943

4. Long $M$ and Rack HJ. Titanium alloys in total joint replacement-a materials science perspective. Biomaterials. 1998; 19:1621-1639. http://dx.doi.org/10.1016/ S0142-9612(97)00146-4

5. Valiev RZ, Islamgaliev RK and Alexandrov IV. Bulk nanostructured materials from severe plastic deformation. Progress in Materials Science. 2000; 45:103-189. http://dx.doi. org/10.1016/S0079-6425(99)00007-9

6. Boyer R, Welsch G and Collings E. Materials Properties Handbook: Titanium Alloys. ASM International; 1998. 1048 p.

7. Zhilyaev AP and Langdon TG. Using high-pressure torsion for metal processing: Fundamentals and applications. Progress in Materials Science. 2008; 53(6):893-979. http://dx.doi. org/10.1016/j.pmatsci.2008.03.002

\section{Conclusions}

The microstructural investigation of the Ti-6Al-7Nb alloy after ECAP followed by thermomechanical processing indicated the formation of ultrafine, some elongated, HCP alpha-Ti grains. SAED analysis suggests there are both low and high angles grain boundaries, which formation can be associated to high dislocation densities introduced during SPD. Analyses of contrast in TEM images have indicated there was crystallographic misfit between contiguous areas with similar diffraction contrast. Based on observations made by TEM an "intrusion grain deformation mechanism" was suggested for nano-scale deformation during ECAP.

\section{Acknowledgements}

The authors acknowledge the support provided by Brazilian agencies FAPESP, CAPES and CNPq.

8. Stolyarov VV, Shestakova LO, Zhu YT and Valiev RZ. A two step SPD processing of ultrafine-grained titanium. Nanostructured Materials. 1999; 11(7):947-954. http://dx.doi. org/10.1016/S0965-9773(99)00384-0

9. Semenova IP, Saitova LR, Raab GI, Korshunov AI, Zhu YT, Lowe TC, et al. Microstructural features and mechanical properties of the Ti-6Al-4V ELI Alloy processed by Severe Plastic Deformation, Proc. of NanoSPD3 Conference Nanomaterials by Severe Plastic Deformation. Materials Science Forum. 2006; 503-504:757-762. http://dx.doi. org/10.4028/www.scientific.net/MSF.503-504.757

10. Inorganic Crystal Structure Database. Crystallographic Information Framework (CIF) files. Available from: <http:// www.fiz-karlsruhe.de/icsd.html>. Access in: 10/07/2011.

11. Cabibbo M, Evangelista E and Scalabroni C. EBSD FEG-SEM, TEM and XRD techniques applied to grain study of a commercially pure 1200 aluminum subjected to equal-channel angular-pressing. Micron. 2005; 36:401-414. PMid:15908224. http://dx.doi.org/10.1016/j.micron.2005.03.004

12. Stolyarov VV, Zhu T, Alexandrov IV, Lowe TC, Valiev RZ. Grain refinement and properties of pure Ti processed by warm ECAP and cold rolling. Materials Science and Engineering. 2003; 343:43-50. http://dx.doi.org/10.1016/ S0921-5093(02)00366-0

13. Iwahashi Y, Horita Z, Nemoto M and Langdon TG. The process of grain refinement in equal-channel angular pressing. Acta Materialia. 1998; 46(9):3317-3331. http://dx.doi.org/10.1016/ S1359-6454(97)00494-1 